\title{
Novel DC-Contact MEMS Shunt Switches and High-Isolation Series/Shunt Designs
}

\author{
Jeremy B. Muldavin and Gabriel M. Rebeiz
}

\begin{abstract}
This paper presents a metal-to-metal contact MEMS shunt switch suitable for DC-40 GHz applications. A novel pull-down electrode is used which applies the electrostatic force at the same location as the metal-to-metal contact area. A contact resistance of $0.15-0.35 \Omega$ is repeatably achieved, and results in an isolation of $-40 \mathrm{~dB}$ at 0.1-3 GHz. The measured isolation is still better than $-20 \mathrm{~dB}$ at $40 \mathrm{GHz}$. The DC-contact shunt switch is used in a series/shunt design to result in $-60 \mathrm{~dB}$ isolation at $5 \mathrm{GHz}$ and better than $-40 \mathbf{~ d B}$ up to $40 \mathbf{G H z}$. The application areas are in highisolation/low-loss switches for telecommunication and radar systems.
\end{abstract}

\section{INTRODUCTION}

$\mathrm{M}$ ICRO -electromechanical (MEMS) series and shunt switches have been successfully demonstrated from 1-100 GHz for low loss switching and phase shifter applications [1], [2], [3], [4], [5]. The series metal-to-metal contact (DC-contact) switch has an off-state capacitance of 2$8 \mathrm{fF}$ which results in high isolation up to $20-40 \mathrm{GHz}$. The loss of the series switch is determined by the contact resistance, and for a contact resistance of $1-2 \Omega$, the loss is 0.1-0.2 dB. Another design is the capacitive switch which has been mostly used in the shunt topology at $10-110 \mathrm{GHz}$ [6], [1]. The capacitive MEMS switch has an up-state capacitance of 30-100 fF and a capacitance ratio of 40-80, resulting in a down-state capacitance of $1.4-3.5 \mathrm{pF}$, and excellent isolation at $10 \mathrm{GHz}$ and above. The capacitive shunt switch is typically built with the anchors attached to the coplanar waveguide (CPW) ground plane (or a microstrip $\lambda / 4$ stub). Muldavin et al. have shown that the capacitive switch can be well fitted using a CLR model and results in very low-loss operation and high-isolation up to $100 \mathrm{GHz}$ and above [2], [6].

This paper details a novel version of the shunt switch topology. The switch is designed to result in a DC-contact with the use of one additional metal layer. The DC-contact shunt switch results in a very low contact resistance due to the use of a novel pull-down electrode, and therefore in high isolation at $0.1-10 \mathrm{GHz}$.

\section{Novel Metal-to-Metal Contact Inline SHUNT SWITCH}

The inline capacitive switch is shown in Fig. 1. The MEMS bridge is defined in the CPW center conductor, and is suspended over a $4000 \AA$-thick layer which connect together the two grounds of the CPW line. The idea of an inline air-bridge has been demonstrated before using standard air-bridge technology and is applied here for MEMS switches. A nitride layer is defined over the central por-

Jeremy Muldavin and Gabriel Rebeiz are with the Radiation Laboratory, Department of Electrical Engineering and Computer Science, University of Michigan, Ann Arbor, Michigan, 49109-2122, USA. muldavin@engin.umich.edu, rebeiz@umich.edu

This work was supported by NASA-Jet Propulsion Laboratory and the National Science Foundation.
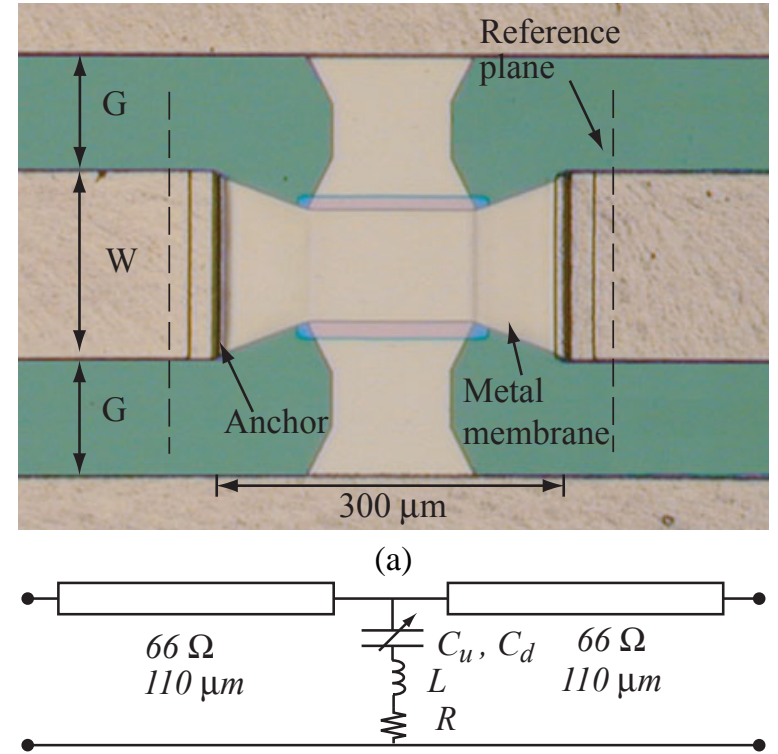

(b)

Fig. 1. Photomicrograph of a X/K-band inline shunt capacitive switch (a) and equivalent model (b).

tion of the bridge, and forms the capacitive contact between the center conductor and the ground plane once the bridge is pulled down. The advantages of this approach is that it isolates the mechanical characteristics of the MEMS bridge from the electrical connection to the ground. In other words, one can now use a narrow high-inductance or a wide low-inductance connection to the ground plane (in a microstrip or CPW implementation) without changing the mechanical spring constant of the MEMS bridge.

Another advantage of the inline switch in the up-state position are the short high-impedance t-line sections due to the height of the bridge. This occurs at the left and right sides of the central bridge portion and help tune out the up-state capacitance. The equivalent t-line impedance is $66 \Omega$ with a length of $100-120 \mu \mathrm{m}$. The model is shown in Fig. 1b.

The inline shunt switch can be made to operate at low RF frequencies (DC-10 GHz) using a metal-to-metal contact (Fig. 2). In this case, two metal layers are defined underneath the bridge. The first layer is the pull-down electrode, and is fabricated using a $3000 \AA$ A-thick layer of gold. The pull-down electrode is connected using high-resistivity bias lines to the edge of the ground plane. A $2000 \AA$ A-thick nitride layer is used to isolate the bias lines from the CPW ground plane. The nitride layer is also deposited over the pull-down electrode. A $4000 \AA$-thick Au layer with is deposited on top of the nitride and is connected to the CPW ground using the "bow-tie"-shaped (low inductance) gold pattern. The top metal layer forms the metal-to-metal con- 


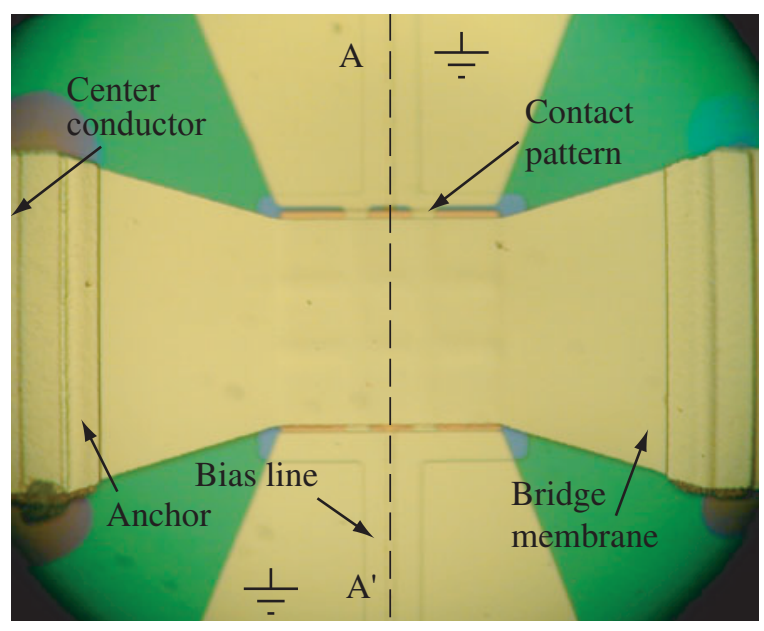

Fig. 2. Photomicrograph of a DC contact inline shunt MEMS switch.

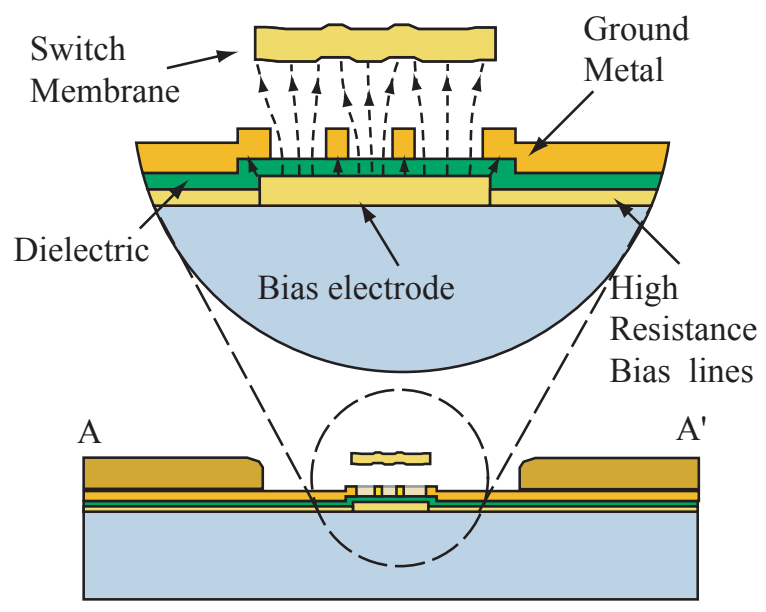

Fig. 3. Illustration of a DC-contact inline shunt MEMS switch. The static electric fields from the bias electrode pull the bridge to the ground contact.

tact with the MEMS bridge, and connects the MEMS bridge to the ground. The MEMS bridge is fabricated as described above using a sacrificial $1.5 \mu \mathrm{m}$-thick layer.

The top metal layer has a $10 \mu \mathrm{m}$ hatch pattern underneath the center of the bridge with openings of $30 \mu \mathrm{m}$-square. The openings are essential to allow the static fields from the pull-down electrode to exert a force on the MEMS bridge. This novel electrode design allows for the placement of the pull-down electrode at the center of the bridge, thereby resulting in maximum bridge deflection for a specific applied voltage. The voltage is applied at the bias electrode and the CPW center conductor is connected to the DC ground.

The inline switch is fabricated in a G/W/G=96/160/96 $\mu \mathrm{m}$ CPW line with a center electrode dimensions of $140 \times$ $100 \mu \mathrm{m}$-square. The pull-down voltage is $35 \mathrm{~V}$ and the applied voltage is $50 \mathrm{~V}$ due to the reduced pull-down area (a result of the metal hatch pattern). The measured up-state capacitance is $130 \mathrm{fF}$ and is the same as the capacitive inline switch described above. The measured contact resistance is very low, around $0.15-0.35 \Omega$, because the electrostatic force is applied at the same location as the metal-to-metal contact area. This may be one of the advantages of this novel design. The switch results in an isolation of $-40 \mathrm{~dB}$ at $0.1-3 \mathrm{GHz}$. The measured isolation is limited by the in-

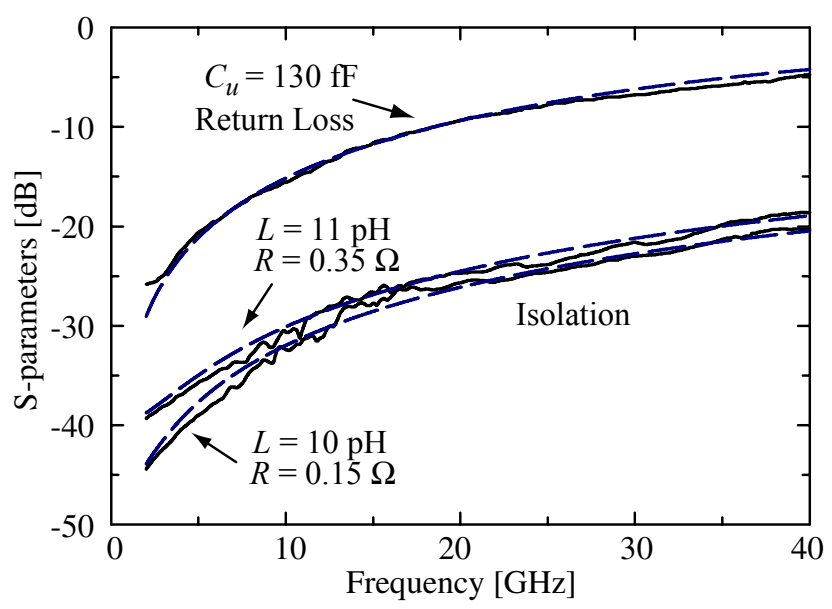

Fig. 4. Measured (solid) and fitted (dashed) S-parameters of an inline shunt DC MEMS switch.

ductance to ground and is better than $-20 \mathrm{~dB}$ at $40 \mathrm{GHz}$. The isolation at $40 \mathrm{GHz}$ can be improved by $6 \mathrm{~dB}$ if a CPW gap of $40-50 \mu \mathrm{m}$ is used, thereby resulting in an inductance of $5-6 \mathrm{pH}$.

The metal-to-metal inline switch can be further improved by choosing different metals with higher contact reliability (AuBe, AuTi, Pt, ErPt, ..) and by fabricating bumps in the MEMS bridge to contact at specific points with a higher pressure per contact. In our case, the contact resistance of $\mathrm{Au} / \mathrm{TiAu}$ was repeatable over two months in laboratory experiments with the wafer dried at $80^{\circ} \mathrm{C}$ for 20 minutes and then flushed with nitrogen before testing. No lifetime tests were done in our laboratory.

\section{High-Isolation Series/Shunt Switches}

An all-metal series switch [7] was integrated with the DC-contact CPW shunt switch to result in a high-isolation series/shunt switch (Fig. 5). Both switches are fabricated in exactly the same process steps, and the only difference are the anchor connections and bias electrodes. The DCcontact shunt switch is $300 \mu \mathrm{m}$ long.

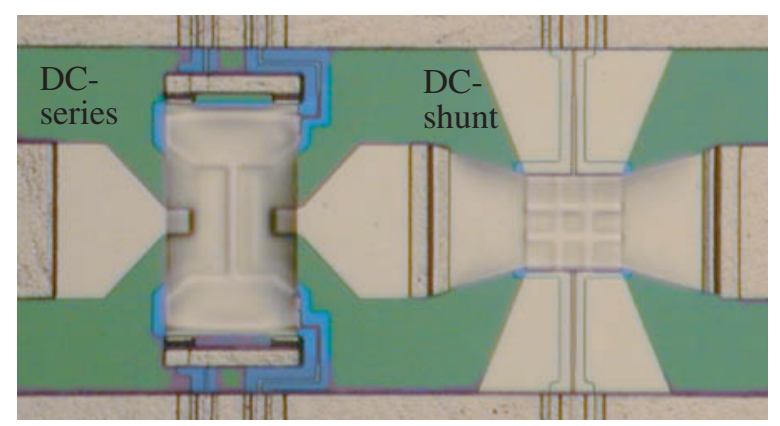

Fig. 5. Photomicrograph of a series/shunt switch with (a) a capacitive shunt switch and (b) a DC-contact switch.

Figure 6 shows the measured isolation of the series/shunt switch when the series switch is in the up-state position and the shunt switch is in the down-state position. The isolation is better than $-40 \mathrm{~dB}$ up to $40 \mathrm{GHz}$. We believe that the intrinsic isolation of the series/shunt is much better than the measured response, but is limited to $-35 \mathrm{~dB}$ by radiation in the 96/160/96 $\mu \mathrm{m}$ CPW line, even at $10 \mathrm{GHz}$. The DC- 
contact shunt switch results in excellent isolation at DC$5 \mathrm{GHz}$ which adds to the isolation of the series switch. The resulting isolation of the series/shunt switch was better than $-60 \mathrm{~dB}$ up to $5 \mathrm{GHz}$.

The measured insertion loss of the series/shunt switch in the pass-state (series-down, shunt-up) was again given by the contact resistance of the series switch and was 0.5 $2 \mathrm{~dB}$ depending on the fabrication run. The measured reflection coefficient in the pass-state was less than $-15 \mathrm{~dB}$ up to $40 \mathrm{GHz}$, and is due to the up-state capacitance of the shunt switch $\left(C_{u}=70 \mathrm{fF}\right)$. If the series switch is fabricated down, the reflection loss does not change, but the insertion loss is less than $0.1 \mathrm{~dB}$ up to $20 \mathrm{GHz}$.

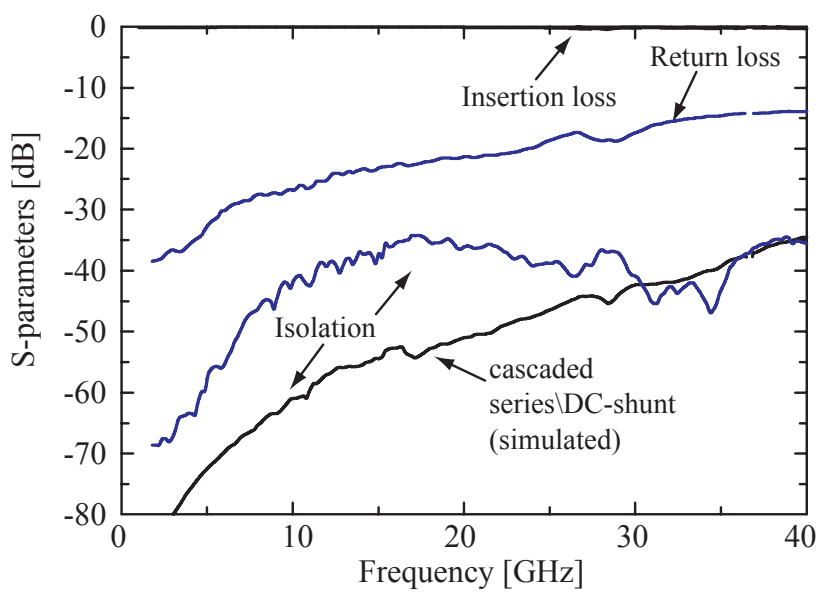

Fig. 6. Measured S-parameters of the MEMS series/shunt switch in the isolation-state and pass-state. The "cascaded" curve shows the isolation of a measured series and shunt S-parameters cascaded in a circuit simulator. The measured insertion loss is for a series/shunt switch with the series switch fabricated in the down-state position.

\section{REFERENCES}

[1] C.L. Goldsmith, Z. Yao, S. Eshelman, and D. Denniston, "Performance of low-loss RF MEMS capacitive switches," IEEE Microwave Guided Wave Lett., vol. 8, pp. 269-271, August 1998.

[2] J.B. Muldavin and G.M. Rebeiz, "High isolation MEMS shunt switches; part 1: Modeling," IEEE Trans. on Microwave Theory and Techniques, vol. 48, no. 6, pp. 1045-1052, June 2000.

[3] R.E. Mihailovich, M. Kim, J.B. Hacker, E.A. Sovero, J. Studer, J.A. Higgins, and J.F. DeNatale, "MEM relay for reconfigurable RF circuits," To Be Published in IEEE Microwave and Wireless Components Letters, Feb 2001.

[4] D. Peroulis, S. Pacheco, and L.P.B. Katehi, "MEMS devices for high isolation switching and tunable filtering," in 2000 IEEE MTT-S Int. Microwave Symp. Dig., Boston, MA, June 2000, pp. 1217-1220.

[5] D. Hyman, A. Schmitz, B. Warneke, T. Y. Hsu, J. Lam, J. Brown, J. Schaffner, A. Walston, R. Y. Loo, G. L. Tangonan, M. Mehregany, and J. Lee, "Surface micromachined RF MEMS switches on GaAs substrates," Int. J. RF Microwave CAE, vol. 9, pp. 348-361, August 1999.

[6] J. Rizk, G.L. Tan, J.B. Muldavin, and G.M. Rebeiz, "High isolation W-band MEMS switches," IEEE Microwave Wireless Components Letters, vol. 11, no. 1, pp. 10-12, January 2001.

[7] J. B. Muldavin and G. M. Rebeiz, "All-metal series and series/shunt MEMS switches," Submitted to IEEE Microwave and Wireless Components Letters, Mar 2001. 